\title{
A Dinâmica da Reforma Administrativa
}

\author{
JOSÉ MEDEIROS \\ Assessor do Diretor-Geral do DASP
}

As atividades administrativas, notadamente as do setor público, não se caracterizam habitualmente pela racionalidade dos métodos de trabalho utilizados. Disso decorre, inexoràvelmente, senão ineficiência, pelo menos a não desejável eficiência, além de tornarem as atividades onerosas em demasia.

E tradicional afirmar-se - em tom dogmático e professoral - que a máquina administrativa brasileira está emperrada e o seu funcionamento é notòriamente deficiente. Isso pode ser considerado um prognóstico, nem sempre fidedigno e sempre sem nenhuma fundamentação técnica. Na realidade, trata-se apenas de uma observação superficial, porquanto não baseada em prévia análise dos fatos de que se originou a atual situação administrativa brasileira. Isso porque as técnicas de administração ainda não estão estratificadas entre nós, constituindo mesmo honrosas exceções quando adotadas na prática, em substituição ao costumeiro empirismo.

Impõe-se realçar que a Administração Pública Brasileira, desde as suas origens coloniais, vem surgindo ao sabor dos acontecimentos, sem a mínima planificação. Outrora, quando apareciam pesSoas, à semelhança de Calógeras e Rio Branco, com bom senso realístico e inata capacidade administrativa, eram logo denominados de grandes administradores. De certo modo, embora desconhecendo os meandros da ciência da Administração, tais homens eram dotados de excepcionais argúcia e fôrça de vontade e que, em virtude de suas inatas qualificaçỗes, chegaram a ultrapassar os obstáculos oriundos daquele desconhecimento. Essas ocorrências, no entanto, devem ser consideradas com suas autênticas características de episodicidade, constituindo, tão-sòmente, fatos pitorescos e de certo relêvo histórico, sem marcar evolução em nosso processo administrativo.

A característica predominante de nossa administração sempre foi a mais completa e anárquica assistematização. Todo e qualquer dirigente de um organismo público se julgava um ADMINISTRADOR, plenamente capacitado para equacionar e solucionar os mais complexos problemas administrativos, sem recorrer - o que seria imprescindivel - a assessorias especializadas.

Semelhante situação, todavia, não poderia perdurar e uma reforma de mentalidade e de comportamento se tornava inadiável. Essse espírito mudancista foi-se corporificando a partir de 1936, por fôrça da Lei n. ${ }^{\circ} 284$, com a instituição do Conselho Federal do Serviço Público Civil e, logo em seguida, com a sua transformação no Departamento Administrativo do Serviço Público, operada pelo Decretolei n. 579 , de 30 de julho de 1938. A época, no órgão recém-criado, que se afamaria sob a sigla DASP, se congregava uma equipe môça, pioneira e algo visionária, sob a liderança de LUIZ SIMŌES LOPES, primeiro Presidente daquela instituição. Essa experiência, no entanto, embora relevante, se ressentia da generalidade necessária à implantação de uma autêntica reformulação da situação existente.

Dêsse modo, o DASP, a princípio isolado como um pequeno farol de tecnicidade na imensidão oceânica do empirismo, e depois com a co-participação da Fundação Getúlio Vargas, representou importante papel no drama de angústia da Administração Brasileira, mas ambos constituíram participaçổes estanques, sem influenciarem, de forma categórica e decisiva, os demais personagens. $\mathrm{O}$ que predominava, ainda, era o primarismo 
administrativo, quase sempre solertemente comandado pelos interêsses pessoais e pela mais nociva influência política.

A análise desapaixonada, sob o prisma exclusivamente científico, do panorama da Administração Pública Brasileira leva o observador imparcial ao mais completo desencanto. Com efeito, de sã consciência, não se pode deixar de reconhecer que o serviço público se apresenta inadequado, sendo preciso dinamizá-lo, a fim de alcançar as finalidades a que se
propõe.

O exigido reaparelhamento da Administração Pública, para atender a tão gigantescas atribuições, sòmente poderá ser realizado através de autêntica revolução àministrativa, considerada a expressão em seu sentido orgânico e em sua concepção funcional.

A desorganização estrutural, na realidade, vem afetando o próprio funcionamento do complexo administrativo, que ainda se ressente de métodos modernos e científicos de trabalho e - suplantando a todos os demais elementos - de pessoal com as qualificações indispensáveis.

Em violenta transposição no tempo e com botas de sete léguas, podemos afirmar, sem sombra de dúvida, que a Revolução de 1964 objetivou, precisamente, estancar a fonte de corrupção e de improbidade administrativa, através de medidas saneadoras, de inquestionável moralidade. Sobrepairando a tôdas, pela sua marcante característica de nova e racional sistematização, encontra-se 0 Decreto-lei n..$^{2} 20$, de 25 de fevereiro de 1967, que estabeleceu as diretrizes para nizaç̃o da Administrativa e para a orga-

E importante ressaltar que se trata de um diploma legal que fixa princípios, com o propósito de nortear e demarcar uma nova filosofia administrativa, ficannormas complementares que corporificassem as diretrizes ali estabelecidas.

A Reforma Administrativa, como é de umà evidência meridiana, não deve representar apenas a reformulação da antiga estrutura, o que constituiria novos cenários para o mesmo drama, mas deve incluir, em seu bôjo, obrigatòriamente, a adoção de uma mentalidade de fato renovadora.

Busquemos o depoimento de uma indiscutível autoridade no assunto: 0 ex-
Ministro Hélio Beltrão. Êle define o seu ponto de vista em têrmos esclarecedores:

"Em nossa opinião, a reforma administrativa não é, bàsicamente, um problema de técnica de organização. E muito mais que isto. E um problema de política ou de filosofia de administração. Antes de nos lançarmos a definir uma nova estrutura de organização, um nôvo organograma, temos que definir a nossa concepção de administração pública e a maneira por que entendemos que ela deve funcionar. importante adotar algumas tomadas de posição preliminares ao problema de organização pròpriamente dito. É necessário conceituar o estilo de govêrno que desejamos praticar". (Reforma Administrativa Departamento de Imprensa Nacional - 1968 - pág. 32.)

Em sentido figurado, pođemos representar a reforma administrativa como um gigantesco polvo, cujos tentáculos há de alcançar os mais variados aspectos da Administração Pública.

Em decorrência, e fundamentalmente, o espírito renovador não pode dissociarse da racionalização das atividades e da simplificação dos métodos de trabalho utilizados. Êsse propósito, no entanto, sòmente poderá ser atingido através da análise administrativa, o que significa, conforme o ensinamento dos técnicos da matéria, o estudo das causas e soluções dos problemas administrativos, abrangendo a responsabilidade fundamental de planejar e aperfeiçoar os processos, os métodos e a estrutura funcional. Com efeito, cabe aos analistas a imensa tarefa de identificar os problemas, determinar as suas causas e propor as soluções. A satisfatória execução de semelhante tarefa requer, por parte dos analistas, dois requisitos básicos: o primeiro é o pleno conhecimento das técnicas de pesquisa científica e o segundo é a capacidade criadora. Essas duas condições são indissociáveis, uma não subsistindo sem a outra. Assim, não basta o técnico obtuso e sem imaginação. Do mesmo modo, nada adianta o imaginativo sem conhecer as

A análise administrativa, cientificamente considerada, no entanto, não vem tendo a desejada aplicação entre nós. Cuidamos que apenas dois exemplos são suficientes para fundamentar tal con- 
O primeiro se relaciona com um problema apaixonante e crucial para o nosso desenvolvimento: a educação nacional. Para essa atividade, os governos revolucionários vêm dando a mais devotada atenção e carreando consideráveis recursos financeiros. Diversas leis já foram promulgadas com o exclusivo propósito de dotar a educação superior brasileira de uma sistemática realmente válida e eficiente. Mas a organização educacional ainda se ressente de funcionalidade, visto não terem sido completamente alijados velhos e arraigados tabus. Paralelamente, os recursos conferidos ao ensino universitário não vem sendo aplicados de forma satisfatória, segundo o consenso geral.

Se procurarmos as causas determinantes de tão flagrante distonia entre o desejo perfeito e a realização incompleta, vamos encontrá-las na deficiência da instrumentalidade, na ausência da científica análise administrativa. Embora identificado o problema, as causas da ineficaz aplicação de recursos não foram linearmente determinadas, nem tampouco as soluções até agora adotadas foram capazes de sanar, de maneira radical, a deficiência.

Não é demasiado reafirmar ser a educação a argamassa fundamental para o desenvolvimento sócio-econômico de um país. Com efeito, o poderio administrativo e o avanço tecnológico defluem, naturalmente, de "fulminante impulso da educação". Impõe-se, portanto, todos os esforços no sentido de tornar eficiente nosso sistema educacional, a fim de podermos extrair - para usar vigorosa expressão de SERVAN SCHREIBER - "um lucro maciço do mais rendoso dos investimentos: a formação de homens". ("O Desafio Americano", 1. a edição brasileira - pág. 66.)

E imperioso, pois, estudar com profundidade 0 atual funcionamento das Universidades, partindo da análise de suas instalações, de seus equipamentos e do material humano de que dispóe, com as vistas sempre erguidas para a eficiência do ensino, para a perfeita integração dos estudantes e dos professôres na vida universitária, para a formulação de uma política financeira em bases prioritárias, a fim de evitar-se o desperdício de recursos, o início de obras que de antemão já se sabe que não serão terminadas em prazơ razoável.

Como um dos resultados positivos dessa análise, poder-se-ia atentar para o efeito psicológico de uma reforma do Ministério da Educação e Cultura e das Universidades em têrmos realísticos, através de uma estrutura organizacional mais reduzida e mais eficiente do que a atual, com acentuada redução das despesas administrativas. Na nova estrutura do Ministério da Educação e Cultura, dever-se-ia prever um dinâmico órgão de pesquisas e de levantamento de dados, com a finalidade específica de realizar a análise do custo operacional do ensino, voltado para a sua racionalização e a justa adequação das despesas de custeio com a sua produtividade.

A tão decantada reforma do ensino superior terá de ser feita através de mudança radical dos métodos didáticos e dos currículos de ensino. Ainda há pouco, o ex-Presidente Costa e Silva se referia à necessidade de, reforçando o período escolar, diminuir o número de anos para a formação de determinados técnicos de que o crescente desenvolvimento nacional tanto precisa, tais como engenheiros, médicos etc.

A par dessa reforma básica de ensino, todavia, cabe a adoção de providências de ordem administrativa, também indispensáveis ao êxito do empreendimento a que se propõe o Govêrno, tôdas elas com o objetivo capital de manter a reformulação em têrmos exequíveis, do ponto de vista econômico-financeiro.

Atualmente, há enorme desperdício de recursos na disseminação de cursos técnicos em tôdas ou quase tôdas as Universidades. Seria conveniente, pois, a unificação total ou parcial de tais cursos, com o propósito de permitir o máximo aproveitamento das atuais instalações e do corpo docente - às vêzes tão escasso em certas regiões onde se situam as Universidades. Dir-se-á que essa medida obstará o acesso aos cursos de estudantes das áreas não atingidas, mas essa dificuldade poderá ser fàcilmente superada com 0 sistema de concessão de bôlsas de estudos, em têrmos realísticos.

Outro obstáculo para o desenvolvimento das atividades de ensino é o dispêndio fabuloso com o custeio administrativo dos órgãos educacionais: instalações nababescas de gabinetes e residências oficiais de dirigentes, número exagerado de funcionários e professôres, concessões de polpudas gratificações etc. Êsse empecilho, no entanto, também poderá ser contornado com a adoção de uma filosofia franciscana, no sentido de proporcionar 
a máxima economia nas despesas de custeio, a fim de ensejar maiores recursos para os programas de ensino como atividade-fim.

Por outro lado, uma das causas da ineficiência do ensino é a proclamada improdutividade do corpo docente: a proporção de um professor para cada quatro alunos é terrivelmente baixa. A par de outras causas, a maior eficiência do ensino depende, poderosamente, de conferir aos professôres um status econômico compatível com a relevância de sua atividade e com sua posição social, o que poderá ser conseguido com a implantação de um nôvo sistema de pagamento (v.g.: retribuição mais condigna, com a exigência de tempo integral e dedicação exclusiva).

Em face do custo elevado e do acentuado caráter social da educação, deve ser convocada a participação do capital privado no financiamento do ensino, através, inclusive, de incentivos fiscais, em virtude de doações, e de renda proveniente da prestação de serviços técnicos e de pesquisas.

Finalmente, é de todo interêsse a participação na direção colegiada dos estabelecimentos oficiais de ensino, inclusive no Conselho Universitário ou órgão semelhante a ser instituído, de representantes proeminentes da comunidade: clero, magistratura, Ordem dos Advogados, Clube de Engenharia, Associação Comercial, Federação das Indústrias etc. Através dessa representação realmente significativa se efetivaria a integração dos órgãos de ensino no meio social.

Outro exemplo eloqüente da ausência de análise administrativa vamos encontrá-lo no plano da política de pessoal.

E fora de dúvida que a implantação de uma autêntica reforma administrativa está umbelicalmente ligada a uma profunda e humanizada modificação na sistemática de pessoal, visto como o resultado positivo daquela reforma repousa no comportamento do elemento humano que lhe dará execução.

Com efeito, não adianta idealizar-se ou mesmo implantar-se a mais moderna máquina administrativa, com a utilização dos mais aperfeiçoados métodos de trabalho, se, para movimentá-la, não se contar com elemento humano capacitado e treinado para realizar as respectivas atividades. Não há como discutir - pois já se erigiu em axioma - que por trás de todo e qualquer empreendimento há sempre o homem, de cujos comportamento e atuação depende o êxito ou o malôgro da emprêsa.

A respeito, merece meditação o seguinte pensamento do especialista norteamericano HERBERT EMMERICH:

"Quaisquer planos de reforma administrativa só poderão ter êxito se com êles vierem atitudes mudadas e maior competência por parte do funcionalismo. Por esta razão, merece a administração de pessoal a mais alta prioridade em qualquer programação de reforma administrativa". (Manual de Administração Pública - F.G.V. - Rio de Janeiro - 1. a ed. - 1962.)

Dentro do panorama que se procurou esboçar, em rápidas pinceladas, a situação atual da Administração de Pessoal no serviço público federal é inexoràvelmente desalentadora. A sua visualização pode ser assim sintetizada: um exército de cêrca de 900.000 servidores, em sua maioria despreparados para a missão que lhes incumbe realizar, sujeitos a uma legislação desordenada e caótica e, além disso, terrivelmente mal remunerado.

De modo geral, os funcionários não estão técnica, intelectual e psicològicamente preparados para o desempenho das atribuições que devem executar. A carência de conhecimentos básicos da matéria a que cabem manipular cotidianamente, irmanada ao desconhecimento ou à imprecisão da importância de sua missão e a do órgão em que trabalham. incapacitam tais funcionários para o cabal exercício de seus cargos. As causas são múltiplas e de suas análise e solução dependem a implantação de um sistema administrativo racional e eficiente.

A incapacidade de realização de suas tarefas, por parte do funcionalismo, é motivada essencialmente pela respectiva forma de ingresso. Apesar das naturais e humanas deficiências, o sistema de concurso constitui, sem sombra de dúvida, o processo mais democrático e eficaz para selecionar os candidatos a cargos públicos. No entanto, o critério habitual de escolha de servidores fugia a essa evidência: era o filhotismo político, onprotecionismo paternalista. Por isso, em previsão certamente otimista, apenas cêrca de dez por cento dos atuais funcionários se submeteram ao crivo seletivo do concurso. Todos os demais - e totalizam mais de 700.000 - ingressaram no serviço público por meios espúrios, por vias transversas. 
Embora a exigência de concurso já fôsse formalmente estabelecida, a Administração e o Legislativo sempre procuraram recursos nem sempre plausíveis para escapar das teias de aranha da exigência legal: os cargos ditos isolados, as funções de contratado e de tarefeiro, os denominados eventuais, credenciados, avulsos ou quaisquer outros apelidos que se lhes dêem. Assim, à margem das previsões fixadas nos quadros permanentes do funcionalismo, proliferaram as mais variadas modalidades de pessoal, cujo ingresso se fazia sem os mínimos requisitos seletivos.

Posteriormente, inúmeras disposições constitucionais ou legais vieram beneficiar os que ocupavam interinamente cargos públicos e os que prestavam serviços sob qualquer das mencionadas formas, destacando-se o parágrafo único do artigo 18 e o artigo 23 do Ato das Disposições Constitucionais Transitórias de 18 de setembro de 1946, o artigo 261 do Estatuto dos Funcionários, as Leis n.os .... 2.284 , de $1954 ; 3.483$, de $1958 ; 3.966$, de $1961 ; 3.967$, de $1961 ; 4.054$, de $1962 ; 4.069$, de 1962 (parágrafo único do artigo 23); e 4.242 , de 1963 (artigo 50). Assim, êsse pessoal estabilizado passou a integrar a categoria de funcionário, com os direitos e vantagens dos antigos titulares, entre os quais os que ingressaram no serviço mediante prévia habilitação em concurso.

Com o advento da Lei $n .^{\circ} 4.345$, de 26 de junho de 1964 (artigo 23), e, posteriormente, da Lei n. ${ }^{\circ} 5.117$, de 29 de setembro de 1966, foi determinada, expressa e inequivocamente, a exigência de concurso para ingresso no serviço público, inclusive para servidores ou empregados submetidos ao regime da legislação trabalhista, a exemplo do denominado "pessoal temporário", previsto no Capítulo IV da Lei n. 3.780 , de 12 de julho de 1960. Êsse princípio, aliás, está consagrado na vigente Constituiçăo ("A primeira investidura em cargo público dependerá de aprovação prévia em concurso público de provas ou de provas e títulos" - artigo $\left.97, \S 11^{\circ}\right)$. A confirmação dessa norma democrática, conjugada com a supressão do nocivo, por mal utilizado, instituto da interinidade, vieram tranqüilizar a primeira investidura no serviço.

Mesmo assim, ainda se vem encontrando recursos e subterfúgios para tergiversar o requisito taxativo, através de pessoas admitidas sem qualquer ato formalizado e retribuídas mediante recibo, com o respectivo pagamento efetuado por do- tações orçamentárias estranhas à especìficamente destinada a "pessoal". Essa prestação de serviços deveria ser eventual e transitória, mas a Administracão vem utilizando o permissivo legal para o ingresso de pessoal técnico, administrativo e auxiliar para a execução de atividades caracteristicamente permanentes. Dêsse modo, não há como fugir ao óbvio: - conjunto de pessoas pagas mediante simples recibo já constitui, em inúmeros órgāos, verdadeiro Quadro de Pessoal, rivalizando e não raro suplantando o corpo permanente de funcionários.

Diante dessa situação de fato, impõese a adoção de providências imediatas e enérgicas, a fim de possibilitar ao funcionalismo desqualificado ou inadequadamente qualificado a aquisição dos conhecimentos indispensáveis ao satisfatório desempenho das atribuições próprias dos cargos de que são ocupantes. O único meio racional para conseguir-se semelhante objetivo seria o treinamento intensivo, através de cursos tècnicamente planejados, nos quais se ministrassem conhecimentos teórico-práticos entremeados com a aprendizagem das técnicas de trabalho normalmente utilizáveis na execucãa das tarefas típicas dos cargos. Incentivar-se-ia, dêsse modo, os funcionários a habilitarem-se ao exercício profissional, certos de que a incapacidade de assimilação dos conhecimentos ministrados nos cursos e a reação negativa ao treinamento seriam fatôres que influiriam, decisivamente, em seu progresso funcional e até mesmo em sua permanência no serviço.

Por outro lado, o problema salarial constitui poderoso e preponderante fator de integração do funcionário público em sua carreira profissional, contribuindo para a permanência do pessoal qualificado, que se vê solicitado, a cada instante, por outros empregadores, com polpudas ofertas pecuniárias. $\mathrm{Na}$ realidade, não se pode admitir a exata idéia de profissionalização sem que o Estado-empregador retribua, condignamente, quem lhe presta serviços. Pela sua relevância, o problema vem sendo debatido em tôdas as áreas ideológicas, inclusive pelos doutrinadores da teoria cristã do trabalho, notadamente através das Encíclicas Papais de caráter social (Leão XIII - Rerum Novarum; Pio XI - Quadragésimo Ano; João XXIII - Mater et Magistra).

No Serviço Público Brasileiro, o problema não tem sido satisfatòriamente equacionado, por uma série infindável de cir- 
cunstâncias. Em princípio, na fixação dos vencimentos, a Administração não considera a situação sócio-familiar de seus funcionários, afastando-se do salário social, preconizado pelos sociólogos católicos como a forma ideal de retribuição do trabalho humano. E de justiça declararse, todavia, que o Estado não se descurou, por completo, dêsse aspecto, visto como procura amenizar a rigidez de seu sistema salarial com a institucionalização do salário-família - complemento da retribuição normal, cujo quantitativo total varia de acôrdo com o número de dependentes que possua o funcionário.

Em seu sentido amplo, o salário se traduz na contraprestação do serviço executado. E na sua fixação devem ser considerados diversos fatôres, tais como o esfôrço físico ou intelectual despendido na realização da tarefa, a relevância da atividade em relação à finalidade da emprêsa ou da entidade e o grau de dificuldade característico do trabalho executado.

Observados tais característicos, o princípio nuclear que deve orientar uma salutar política salarial é o da uniformidade de tratamento no tocante àqueles que executam trabalho de idêntica natureza ou de igual graduação de complexidade. E tradicional e inexpugnável o princípio de salário igual para idêntico trabalho, consagrado universalmente pela doutrina e pela legislação. A inobservância dessa norma fundamental, de caráter mesmo axiomático, acarreta profundas injustiças, com sérias implicacões no moral da equipe incumbida de realizar as atividades da organização. No Serviço Público Brasileiro, em particular, o descumprimento dêsse princípio vem provocando descontentamento generalizado do funcionalismo e ocasionando encadeadas reivindicações: administrativas, legislativas e judiciárias.

Com o decurso do tempo, ao invés de solucionar tão cruciante problema social, que afeta o sistema de vida e o bem-estar familiar de vários milhões de pessoas, a tendência vem sendo de agravá-lo cada vez mais, sob a maléfica influência da espiral ascendente do custo de vida, deglutidora insaciável dos frutos do trabalho de quem percebe salário fixo, apesar dos meritórios esforços do Govêrno no sentido de abater ou pelo menos domesticar o monstro da inflação.

Urge, portanto, uma criteriosa reformulação da política salarial no tocante ao funcionalismo federal, inclusive com o propósito de abandonar o nocivo e discriminatório apêlo a recursos esdrúxulos e condenáveis de aumentos camuflados de vencimentos: a aplicação quase indiscriminada do regime excepcional do tempo integral e dedicação exclusiva, a extensão da gratificação pela representação de gabinete além de sua destinação específica, - pagamento extraordinário, mediante recibo, a pretexto de execução de trabalhos técnicos ou especializados etc.

No entanto, o problema salarial do funcionalismo sòmente poderá ser integralmente solucionado com a revisão do atual Plano de Classificação, implantado pela Lei n. 3.780 , de 12 de julho de 1960 , que objetivou a uma planificação racional dos cargos e funções então existentes no Serviço Público Civil do Poder Executivo, com o elevado propósito de corrigir as anomalias decorrentes da assistematização reinante.

É certo que, do ponto de vista estritamente técnico, o Plano de Classificação de Cargos constitui instrumento de trabalho dissociado de qualquer Plano de Pagamento ou de Remuneração. Essa dissociação, porém, não é completa nem absoluta. Isso porque a Classificação de Cargos terá de ser planejada atentandose para múltiplos fatôres, inclusive o sistema de retribuição vigente ou a vigorar no futuro, havendo, quase sempre, necessidade de reciprocas adaptação e coordenação.

No caso brasileiro, as modificações introduzidas na proposta executiva de sistematização dos cargos públicos, durante a sua tramitação legislativa, complementadas com as porventura bem intencionadas correções ou distorções parciais, em sua fase de execução, desfiguraram por completo o planejamento originário, tornando-se imperiosa e inadiável a sua reformulação, simultâneamente com as demais medidas preconizadas no presente artigo, a fim de possibilitar à Administração Pública Federal contar com equipes homogêneas de funcionários capazes de executar, com pleno êxito, a reforma administrativa já em fase inicial de implantação.

Em estudo anterior, apresentado ao Govêrno como simples contribuição, precozinamos uma nova estratégia de pessoal na Administração Pública Federal. 
Nesse trabalho, acentuamos que a situação do funcionalismo poderia ser equacionada sob tríplice aspecto:

1. $\left.{ }^{\circ}\right)$ FISICO - condições humanas de subsistência, dignificando o exercício da função pública, o que sòmente seria alcançável através de justa revisão da política salarial do Govêrno.

2.) PSICOLÓGICO - treinamento adequado, com o propósito de capacitar o funcionário ao eficiente desempenho das atribuições de seu cargo, incutindo-lhe a importância de seu trabalho no conjunto das atividades administrativas.

3. ) FINANCEIRO - eliminação programática das despesas gerais de pessoal, o que se conseguiria com a gradativa diminuição do número de servidores, em conseqüência natural de efetivação de critérios de incentivo financeiro.

Tais objetivos poderiam ser alcançados com a implantação, imediata ou em caráter de prioridade e de urgência, das seguintes medidas:

1. ANÁLISE pormenorizada do trabalho executado pelo funcionalismo, qualitativa e quantitativamente, em face das atividades específicas dos órgãos integrantes da Administração Pública Federal.

1.1 - Simultâneamente, d e ve r-se-ia realizar aprofundada análise das atividades administrativas, o que serviria de base técnica para a ideal organização e para a implantação de métodos racionais de trabalho, em cumprimento aos princípios inscritos na Lei da Reforma Administrativa (Decreto-lei n. ${ }^{\circ} 200$, de 25 de fevereiro de 1967).

2. REVISÃO geral do atual Plano de Classificação de Cargos, no sentido de reestruturar e simplificar a sistemática vigente, implantando-se, simultâneamente, nôvo Plano de Pagamento, ajustado à realidade do mercado de trabalho e destinado a retribuir, condignamente, os funcionários capacitados.

2.1 - No nôvo Plano de Classificação seria previsto o número de cargos estritamente necessário à realização das atividades governamentais inferior ao número atualmente existente, tendo em vista, inclusive, a racionalização dos métodos de trabalho e a implantação de nôvo pe- ríodo - horário de atividades funcionais.

2.2 - O Plano de Classificação seria instituído "em aberto", ficando o preenchimento dos cargos, através de transposição, na dependência de atenderem os atuais funcionários às condições de habilitação exigidas: cursos de treinamento específico, com provas finais semelhantes às de concurso público.

2.3 - Nos novos Quadros sòmente seriam incluídos os funcionários comprovadamente qualificados, de acôrdo com a alínea anterior, os quais passariam a constituir o núcleo permanente do Serviço Civil.

2.4 - Os funcionários incluídos nos novos Quadros ficariam ainda sujeitos a um período de plena adaptação ao trabalho e sòmente seriam considerados enquadrados, em caráter definitivo, se confirmados no exercício do cargo, através dêsse estágio probatório.

2.5 - Os funcionários que não se submeterem ao meio de aferição de capacidade (alínea 2.2), ou nêle forem inabilitados, continuariam na mesma posição atual (quadros extintos e com vencimentos menores).

3. CONSTITUIÇÃO de uma comissão especial para encarregar-se dos trabalhos de elaboração dos novos Planos de Classificação de Cargos e de Pagamento.

4. TREINAMENTO intensivo e obrigatório, abrangendo todo o funcionalismo, desde os ocupantes dos cargos ou funções de direção, chefia ou assessoramento, alcançando os servidores que exercem atividades técnicas ou científicas, até os executantes das mais simples tarefas, visto como tôdas as atividades humanas exigem conhecimentos e aptidões adequados.

4.1 - Aos funcionários habilitados em cursos de treinamento específico conceder - s e-i a m incentivos pecuniários, em bases percentuais ao vencimento, e variáveis de acôrdo com a natureza do curso e sua importância pragmática para a Administração, considerando o interêsse do serviço.

5. REAPARELHAMENTO do Departamento Administrativo do Pessoal Civil DASP - , que se encarregaria de executar ou supervisionar o programa de treinamento acima exposto sumàriamente. 
5.1 - Mecanização do cadastro do pessoal da Administração Direta e Indireta, através da aquisição do instrumental indispensável.

5.2 - Colaboração sistemática dos órgãos federais, no sentido, inclusive, de ceder funcionários qualificados para formação das novas equipes de trabalho.

5.3 - Instalação definitiva do Centro de Aperfeiçoamento, em Brasília, dotado, além da parte administrativa, de salas de aula-laboratório, restaurante, lavanderia e demais instalações necessárias. O Centro funcionaria em estreita e constante cooperação com a Escola de Serviço Público - ou mesmo absorveria as atuais atribuições dessa unidade organizacional - na realização dos programas de treinamento funcional.
5.4 - Instalação de gráfica própria, destinada a atender às imediatas exigências na confecção de publicações e demais materiais de estudo necessários ao treinamento funcional.

Os delineamentos das presentes considerações se fundam, necessàriamente, na análise administrativa, planejada e realizada em bases metódicas, como instrumento indispensável ao aprimoramento do Serviço Civil Brasileiro. Isso porque já é tempo de relegarmos as soluções apressadas e empíricas, quase sempre dissociadas da realidade. Cuidamos que os brasileiros já possuímos a experiência necessária para buscarmos, para os problemas administrativos que nos afligem, soluções tècnicamente satisfatórias, alicerçadas nos princípios da ciência ou da arte da administração. 